El contenido de esta obra es una contribución del autor al repositorio digital de la Universidad Andina Simón Bolívar, Sede Ecuador, por tanto el autor tiene exclusiva responsabilidad sobre el mismo y no necesariamente refleja los puntos de vista de la UASB.

Este trabajo se almacena bajo una licencia de distribución no exclusiva otorgada por el autor al repositorio, y con licencia Creative Commons - Reconocimiento de créditos-No comercial-Sin obras derivadas 3.0 Ecuador

\title{
c) creative
}

\section{Chronic pesticide poisoning from persistent} low-dose exposures in Ecuadorean floriculture workers: toward validating a low-cost test battery

Jaime Breilh, Nino Pagliccia, Annalee Yassi 


\title{
Chronic pesticide poisoning from persistent low-dose exposures in Ecuadorean floriculture workers: toward validating a low-cost test battery
}

\author{
Jaime Breilh', Nino Pagliccia², Annalee Yassi ${ }^{2}$ \\ ${ }^{1}$ Universidad Andina Simón Bolivar, Quito, Ecuador, ${ }^{2}$ University of British Columbia, British Columbia, Canada
}

\begin{abstract}
Chronic pesticide poisoning is difficult to detect. We sought to develop a low-cost test battery for settings such as Ecuador's floriculture industry. First we had to develop a case definition; as with all occupational diseases a case had to have both sufficient effective dose and associated health effects. For the former, using canonical discriminant analysis, we found that adding measures of protection and overall environmental stressors to occupational category and duration of exposure was useful. For the latter, factor analysis suggested three distinct manifestations of pesticide poisoning. We then determined sensitivity and specificity of various combinations of symptoms and simple neurotoxicity tests from the Pentox questionnaire, and found that doing so increased sensitivity and specificity compared to use of acethylcholinesterase alone - the current screening standard. While sensitivity and specificity varied with different case definitions, our results support the development of a low-cost test battery for screening in such settings.
\end{abstract}

Keywords: Pesticide poisoning, Chronic exposure, Neurobehavioural Evaluation System (NES2), Biomarker indices of toxicity, Ecuador, Floriculture validity of acetylcholine esterase, Environmental stressors

\section{Introduction}

The Granobles River Basin in Cayambe of North Andean Ecuador is an excellent location for cut flower plantations, with $60 \%$ of the land currently in use for rose production in the country. ${ }^{1,2}$ Cut flowers (mostly roses), destined for markets in Europe, North America, and Asia, constitutes an important export product for Ecuador. Nonetheless, the floriculture industry is inadequately monitored for adherence to sustainable agricultural standards. This has resulted in the continued extensive use of toxic pesticides, including those belonging to Class I (extremely or highly hazardous) and II (moderately hazardous) as designated by the World Health Organization. ${ }^{3}$ Global economic forces on this industry have contributed to pressure for production of high yields for export and have resulted in limited attention to the environmental and health effects of pesticide use on agricultural workers and neighboring rural communities. ${ }^{4}$ Pesticide contamination is thought to be widespread in the traditional agrarian communities also situated in this prime agricultural land, as a result of 'green

Correspondence to: Annalee Yassi, University of British Columbia, British Columbia, Canada, Email: Annalee.Yassi@ubc.ca revolution practices, ${ }^{5}$ as well as chemical drift, runoff, and leaching from the neighboring cut-flower plantations, careless disposal of pesticide containers, domestic pesticide use, and the reusing of plastic sheets from cut-flower greenhouses within the communities (Fig. 2 and 3).

A wide range of pesticides are used on the farms and there is limited knowledge among the workers regarding the classes of chemicals used, safe practices, and proper application. ${ }^{1}$ Workers are directly exposed to pesticides through skin contact, inhalation, and/or ingestion while working in the greenhouses, trimming and classification rooms, and refrigerated rooms where the flowers are preserved and packaged for export (Fig. 4). ${ }^{1}$ It is difficult to monitor exposure due to the use of various classes of pesticides, task rotation, the frequent practice of chemically intensive domestic agriculture by workers, and the widespread contamination in neighboring communities. Additionally, morbidity is under-reported among agricultural workers, ${ }^{6}$ thus, assessing the extent of pesticide poisoning remains challenging.

Heavy pesticide use on farms has been documented with self-reported symptoms and acute pesticide poisoning in low- and middle-income regions worldwide, 


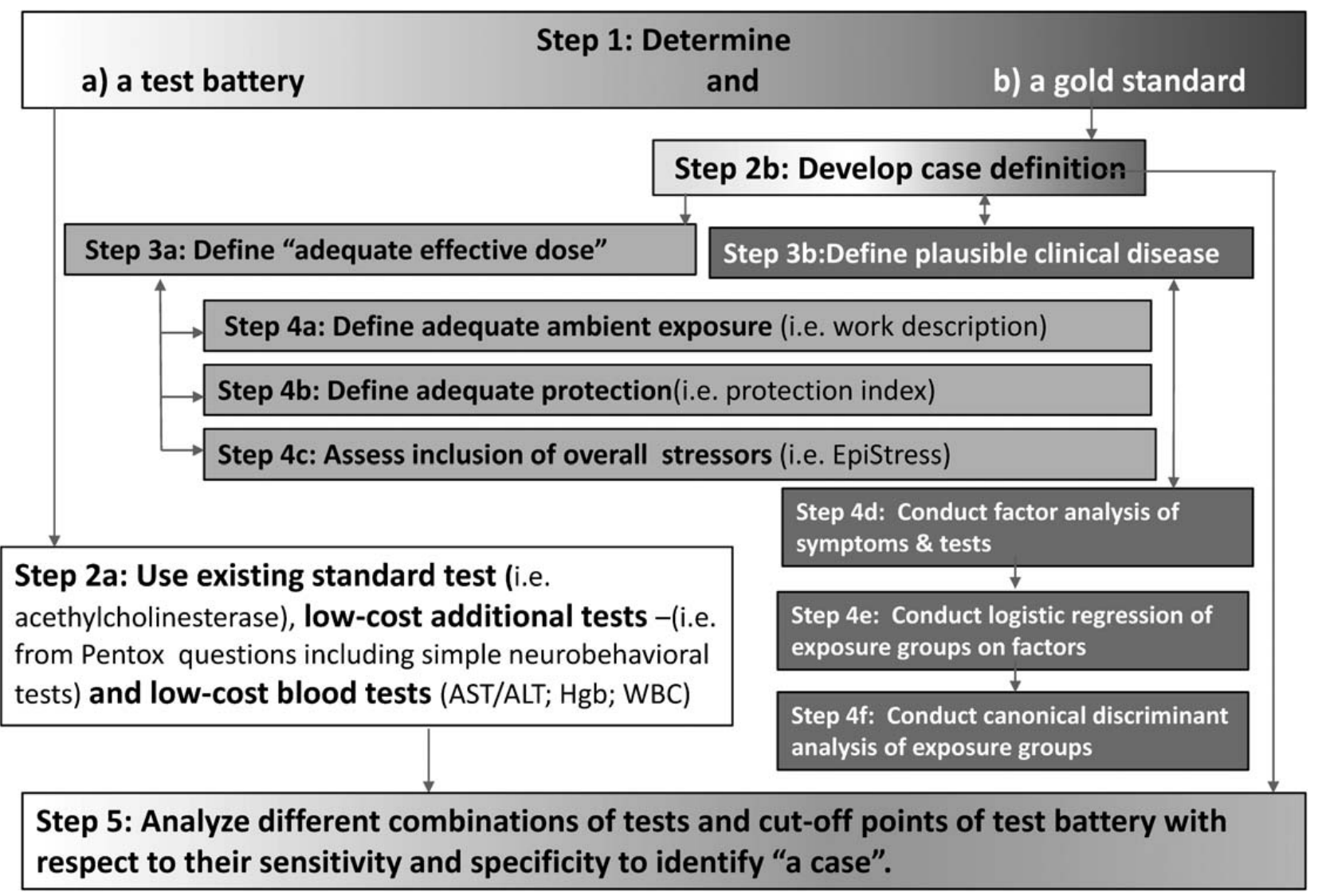

Figure 1 Developing a low-cost test battery to identify a possible case of chronic pesticide poisoning.

including Vietnam, ${ }^{7}$ the Gaza Strip, ${ }^{8}$ South India, ${ }^{9}$ and Ecuador, ${ }^{1,10,11}$ with a wide range of adverse human health effects, depending on the chemicals employed. There have also been reports of genetic damage attributable to pesticide exposure in Ecuadorian, ${ }^{12}$ as well as in Mexican, cut-flower workers, ${ }^{13}$ and in Spanish greenhouse workers. ${ }^{14}$ Chronic exposure to organophosphates (OP) pesticides has been linked to increased risk of liver dysfunction, and associated with elevated levels of liver enzymes, including alanine aminotransferase (ALT) and aspartate aminotransferase (AST) in rodents ${ }^{15}$ and in humans. ${ }^{16}$ Decreases in hemoglobin $(\mathrm{Hg})$ and hematocrit values as a result of pesticide exposure have also been documented as well as changes in white blood cell (WBC) counts. ${ }^{17}$

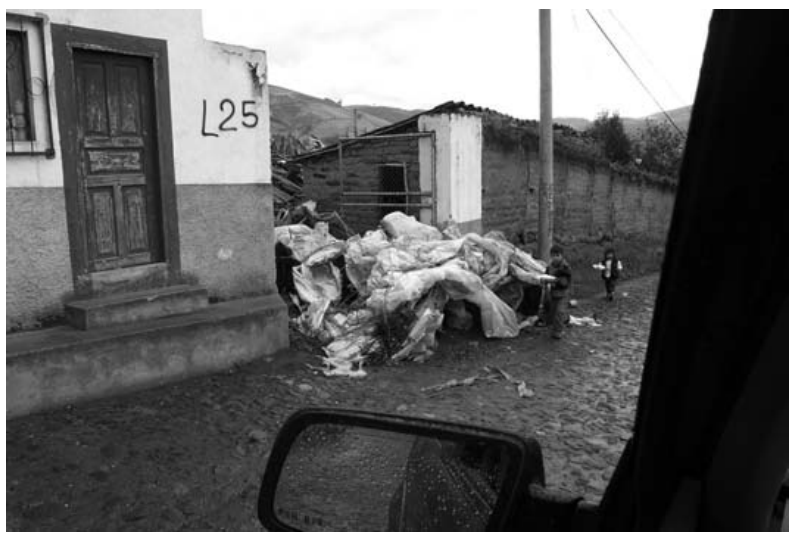

Figure 2 Children often play in the contaminated plastics.
Wesseling et al. ${ }^{18}$ documented important gaps in occupational health in Central American countries noting little reporting of occupational diseases from pesticide use. Pesticide surveillance in Ecuador remains limited to extreme cases of poisoning based on hospital reports. ${ }^{10}$ Measures of erythrocyte acetylcholinesterase (AChE) and plasma AChE (buChE) are commonly used as indicators of OP and carbamate exposure. For the detection of acute toxicity, AChE readings are only useful when there are baseline measurements; there is widespread agreement that in a setting of low-dose chronic exposure, a single AChE reading provides very limited information. This test is, nonetheless, the only test being used in Ecuador today as the recommendation of three baseline tests of AChE after 30 days of nonexposure, prior to a test postexposure is simply not logistically - or financiallyfeasible. Few agricultural workers receive sufficient doses to cause acute effects from pesticide exposure, but most workers are continuously exposed to mixtures of chemicals in low doses. ${ }^{19}$ McCauley et $a .^{20}$ have suggested that AChE should be complemented with supplemental testing.

Some excellent work has recently been completed by Bravo et al. ${ }^{21}$ in the Program of Work and Health in Central America (SALTRA) in establishing a monitoring system for pesticide use and a set of indicators have been developed to monitor regulatory observance of international agreements. However, the extent of 


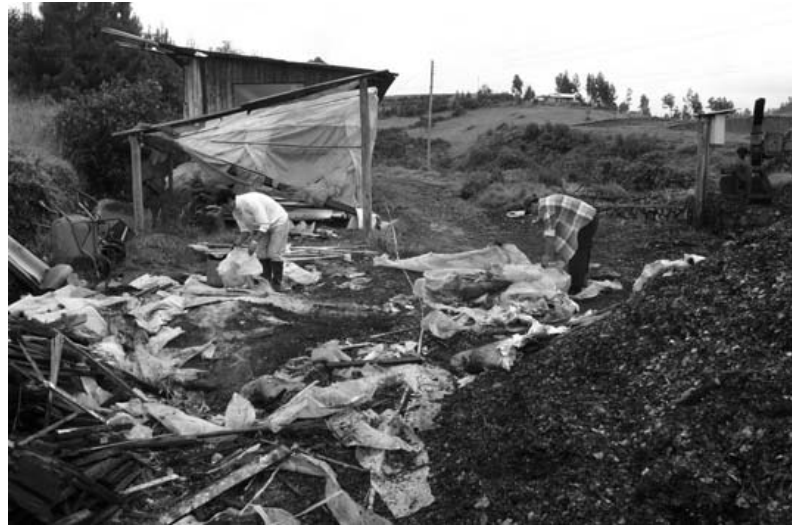

Figure 3 Pesticide contaminated plastic is a source of environmental contamination.

chronic pesticide poisoning from combinations of lowdose persistent exposure remains unknown. The new constitution in Ecuador, resoundingly approved by the population, ${ }^{22}$ gives new impetus for improved control measures for a healthy environment. As chronic pesticide poisoning from persistent low-dose exposure is difficult to diagnose, we sought to develop a low-cost test battery to apply in such settings.

\section{Methods}

\section{Overall Approach}

Figure 1 outlines the approach we took to accomplish the previously stated objective. The well-accepted approach would be to evaluate screening tests against a gold standard for the diagnoses (Step 1). ${ }^{23}$ However, as there is no gold standard, we decided to evaluate index. screening tests by determining their ability to detect pesticide-poisoning cases. To do this, we identified potential tests to both include in a battery (Step 2a) and develop a case definition (Step 2b). The entity we were interested in detecting was a 'case of physiological abnormalities consistent with what the toxicological literature has shown is likely attributable to persistent low-dose exposure to pesticides, in a person who has sustained such exposure, and has no other readily apparent explanation for these abnormalities.' As with any occupational disease, a case must have incurred not only exposure, but sufficient

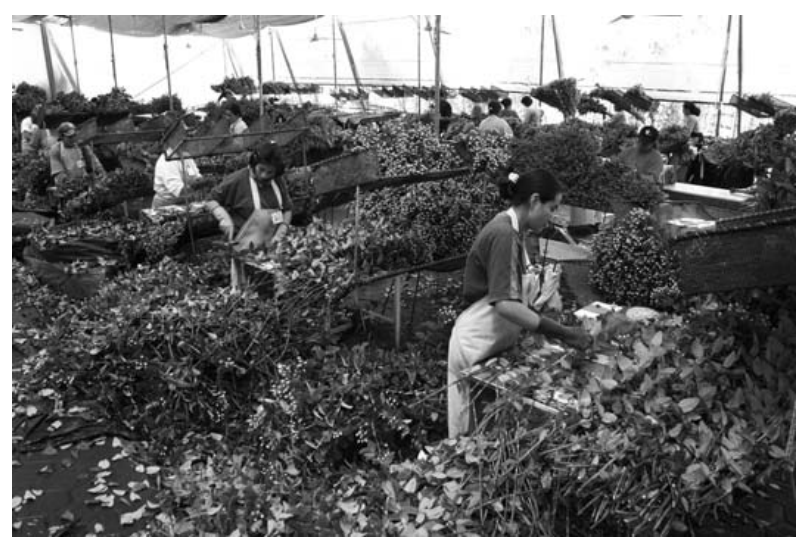

Figure 4 A large portion of the workforce are young women. effective dose (Step 3a) as well as have also demonstrated plausibly related health effects (i.e., consistent with the known toxicity) (Step 3b). Development of a working case definition, therefore, had two components: First, we had to establish a quantification of exposure that could result in health effects; and second, we had to define these health effects.

To define an 'adequate effective dose,' we examined three components: estimation of ambient exposure based on a description of exposure of various occupational groups using not only standard methods of job descriptions and duration of exposure (Step 4a), but also applying a protection index to take control measures into account (Step 4b). We also wished to consider a qualifier to take into consideration the knowledge that the occupational exposure is only one component of the full dose of pesticides and related environmental stressors to which these workers would be exposed in their daily lives. ${ }^{24}$ Thus, given the known mechanisms of toxicology and the importance of combined environmental stressors ${ }^{25-27}$ in determining the ultimate tissue toxicity (or effective dose, in essence), we also sought to explore the usefulness of adding a measure of overall environmental stressors (Step 4c). To define plausible clinical disease, we used factor analysis to characterize clinical patterns (Step 4d). We then proceeded to the fifth step, namely, we tested various combinations of screening tests against various case definitions, as discussed later.

In the following sections we outline: 1) the setting and recruitment; 2) questionnaires and clinical tests; 3) defining cases of pesticide poisoning and test batteries; and 4) statistical analyses.

\section{Setting and Recruitment}

Cultivation workers, who plant, trim, and maintain the roses until they are ready for harvesting, typically use masks, gloves, overalls, and boots to protect against pesticide residues, and they are not supposed to reenter the greenhouse sooner than minimal waiting periods according to the type of chemical applied in spraying. Post-harvest, cold room and packaging workers process the roses for export. While in a refrigerated room, they sometimes dip the flowers into pesticides to protect them from contamination and they apply chemical preservatives that enhance plant vitality and prepare them for export. The flowers are then grouped into bouquets according to the style, length, and color desired by the destination country (Fig. 5). The leaves are trimmed and the flowers are packaged while remaining in the refrigerated room until further transported for export. The post-harvest workers responsible for dipping the flowers in chemicals are supposed to use full protective equipment (waterproof and impermeable overalls, rubber boots, 




Figure 5 Flowers are grouped into bouquets as requested by the destination country.

gloves, and long-sleeved jackets) as well as a respiratory mask with a filter (Fig. 6). The fumigators are responsible for mixing the pesticides and spraying the flower fields. They are not supposed to spray for more than four hours each shift and they must rotate from fumigation to another section, ensuring that they spend double the time in fumigation in a lower exposure setting (e.g., one week in fumigation; two weeks in cultivation). Maintenance/service workers are generally not situated directly in the greenhouses, but conduct odd jobs around the farm; these workers are not likely to be directly exposed to chemicals.

Fieldwork and collection of data took place in 2008. Permission was granted to conduct the study on

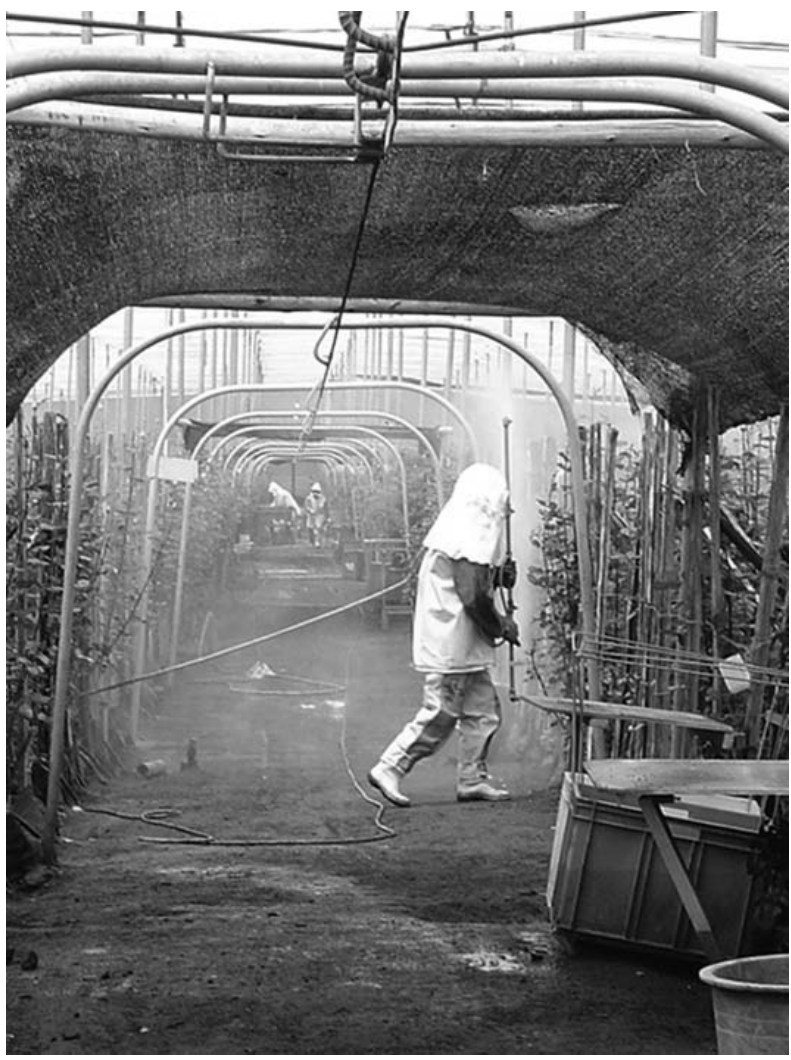

Figure 6 The greenhouse: one of multiple locations of low dose chronic exposure in floriculture. Flower plantation workers breathe, touch and ingest chemical residuals. two rose farms in the region. We recruited both men and women workers of various positions within the farm between 18 and 69 years of age by promoting the study in a large group meeting and inviting workers to attend a testing session during working hours. The study was designed and conducted with full involvement of worker and employer representatives. All norms of informed consent, privacy protection, confidentiality, and avoidance of potential risks to participants were ensured to the satisfaction of all stakeholders, researchers, funding agencies, and institutional partners. The objectives of the study were explained in detail to managers, employees, and residents at each site using dialogue common to the area; and consent to participate was obtained from each individual.

In order to focus on cases that were clinically relevant (i.e., had clinical abnormalities that had a reasonable probability of being primarily related to pesticide exposure rather than other causes), individuals with previous or concurrent medical conditions (e.g., epilepsy, kidney or liver disorders, diabetes, anemia), past cerebral trauma, or prescribed medication were excluded from analysis. Smokers and individuals who reported excessive alcohol use or had consumed alcohol within 48 hours of the testing described in this study were also excluded. Thus, the original sample size of 160 was reduced to 123 .

\section{Questionnaires and Clinical Tests}

For each worker, we gathered information regarding exposures and health outcomes by an interviewer administering two questionnaires (Pentox and EpiStress) and clinical tests. We then calculated an exposure index. The Pentox questionnaire included questions about exposure, work practices, and personal protective equipment (PPE) used, as well as symptoms. Specifically, the Pentox set of questions, as described in-depth in Breilh et al., ${ }^{28}$ developed by the Health Research and Advisory Center (CEAS) in Ecuador for community participative screening of exposure and human health impacts of agricultural chemicals, encompasses three elements: occupational identification; worker exposure/protection conditions; and clinical indicators of health impacts of chemicals. We used a scoring system previously designed to measure compliance with international worker protection norms in different work sections of a productive unit, as defined by international standards for cut flower production. ${ }^{28}$ We established a set of items related to specific protection gear and norms as follows: 8 items for basic measures for all sections; adding 4 specific measures for the crop area; 3 specific items for cold room workers; and 4 additional items for postharvest workers. Each protection item fulfillment was evaluated on a three point scale ( 0 for no application of norms; 1 for regular application and 2 
for complete application), and the section's score was established by adding the item scores. For example, the possible results for a 'crop' worker could range from an excellent compliance level of 24 points (8 general items +4 specific crop section items $=12$ items $\times 2$ ) to a minimum 0 points score, if none of the norms/gear protections were present. In this case we combined and rescaled the scores to range from 0 - for no compliance to protection - to 24 for full compliance to protection, such that if a worker scored 20 points then the resulting index would be 0.83 compliance.

The health outcomes captured in the Pentox questionnaire (listed in Table 3) include the 16 most frequent symptoms described by occupational epidemiological research as associated with toxicity, plus three basic tests: hand-eye coordination, symbolvisual integration, and recent memory.

The EpiStress questionnaire designed by Breilh, was also used, as previously mentioned. This is a selfadministered questionnaire containing 28 items covering the following components: five items referring to work process stressors; three items covering domestic environmental stressors; seven items referring to tensions of basic living conditions (food, housing, rest and recreation, transportation, and debts); four items covering neighborhood pollution and safety; five items accounting for affective and family relation stressors; two items related to physical impediments; and two items related to extreme suffering or loss of a family member. The items are measured on a Likert scale scored as: $0=$ never; $1=$ seldom; $2=$ many times; and $3=$ always. To avoid endpoint bias, we recoded each item using the Goldberg dichotomous scale, 0 or $1=0$ (low) and 2 or $3=1$ (high), which yields a $0-28$ point score range. Details about content validity and consistency of this instrument have been previously reported. ${ }^{29,30}$

Clinical tests administered by specialized personnel included standard blood tests and AChE. After an overnight fasting period, venous blood samples were collected in the appropriate containers and the tubes maintained in cold chain and preserved until reaching the laboratory within four hours. Blood samples were analyzed by the Universidad Central del Ecuador Medical School's Biomedical Laboratory, a certified laboratory. The AChE readings were processed by the Test Mate ChE from EQM Research Inc., a field kit that measures erythrocyte AChE and hemoglobin for correcting the readings for hemoglobin $(\mathrm{Hg})$, which varies with altitude.

\section{Defining Cases of Pesticide Poisoning and Test Batteries}

Case Definitions. To develop a case definition we defined effective dose both with and without EpiStress (in order to evaluate the importance of the stress factor in the manifestation of toxicity, as noted previously). If the sensitivity and specificity were almost the same with and without considering the impact of stressors, that would mean that the stress factor does not intervene significantly in determining outcome, as defined by our various case definitions. We defined health effects using either a blood test marker of a systemic effect or NES2 as a marker of neurotoxicity. As these case definitions were used to assess sensitivity and specificity of batteries, we were careful not to include the same tests or symptoms in the case definition as were used in screening tests, in order to avoid a tautology.

Batteries of Screening Tests. Several tests, more specifically several tests based on the Pentox questionnaire symptoms plus or minus simple low-cost blood tests (including AChE), were defined to assess how sensitive and specific they are in identifying a 'case.' A series of tests, selected from the Neurobehavioural Evaluation System (NES2), ${ }^{31}$ which has been used in other studies, ${ }^{32-34}$ was used as well. Administered by personnel trained to assess neurological function in pesticide-exposed participants, we selected finger tapping (to measure motor speed and control), reaction time (to evaluate response speed), hand-eye coordination, pattern memory score (to test visual nonverbal memory), and symbol digit latency (to measure coding and complex functioning). These tests were selected based on their sensitivity to chronic pesticide exposure documented in previous studies, ${ }^{35}$ and to minimize cultural barriers, as this system was originally designed for use in northern, English-speaking countries. Also, although some experts promote NES2 as the measure to identify cases of chronic pesticide exposure, ${ }^{31}$ it is not clear whether the NES2 is adequate for identifying cases in which the predominant impact is on organ systems other than the neurological system. This gave us the additional incentive to include NES2 in this study.

\section{Statistical Analysis}

First, descriptive analyses were performed on the questionnaire items with respect to exposures (including occupation and work practices (Step 4a), protection index (Step 4b), and EpiStress results (Step 4c) as well as symptoms and their relationship with exposure. To reduce the large number of tests and symptoms in the various instruments used to a smaller number of meaningful factors, we performed factor analysis (Step 4d). As presented in details in the Results section, three distinct factors were identified and three sets of factor scores were obtained for each individual as a linear combination of all intervening variables weighted by their factor loadings.

Next we performed a logistic regression analysis using the factor scores as independent variables to 
Table 1 Workers' baseline information by type of job

\begin{tabular}{|c|c|c|c|c|c|c|c|c|c|c|c|c|c|}
\hline \multirow{4}{*}{$\begin{array}{l}\text { Respondents (\%) } \\
\text { Age (SD) } \\
\text { Years in Floriculture (SD) }\end{array}$} & \multirow{2}{*}{\multicolumn{2}{|c|}{$\frac{\text { Cultivation }}{60(48.8)}$}} & \multirow{2}{*}{\multicolumn{2}{|c|}{$\frac{\text { Post Harvest }}{30(24.0)}$}} & \multirow{2}{*}{\multicolumn{2}{|c|}{$\frac{\text { Fumigation }}{9(7.3)}$}} & \multirow{2}{*}{\multicolumn{2}{|c|}{$\frac{\text { Fertilization }}{5(4.1)}$}} & \multirow{2}{*}{\multicolumn{2}{|c|}{$\frac{\text { Maintenance }}{14(11.4)}$}} & \multirow{2}{*}{\multicolumn{2}{|c|}{$\frac{\text { Administration }}{5(4.1)}$}} & \multirow{3}{*}{$\begin{array}{c}\text { Total } \\
123(100) \\
32.6(9.7)\end{array}$} \\
\hline & & & & & & & & & & & & & \\
\hline & 32.8 & $(8.1)$ & 29.9 & $(8.4)$ & 26.8 & $(9.4)$ & 28.6 & $(8.8)$ & 40.2 & $(14.4)$ & 40.2 & $(14.4)$ & \\
\hline & 9.9 & $(5.0)$ & 7.5 & $(5.0)$ & 4.2 & $(4.3)$ & 8.3 & $(4.6)$ & 9.2 & $(5.1)$ & 10.9 & $(2.9)$ & $8.8(5.1)$ \\
\hline \multicolumn{14}{|l|}{ Gender \% } \\
\hline Female & \multicolumn{2}{|c|}{30.0} & \multicolumn{2}{|c|}{66.7} & \multicolumn{2}{|c|}{11.1} & \multicolumn{2}{|c|}{20.0} & \multicolumn{2}{|c|}{7.1} & \multicolumn{2}{|c|}{60.0} & 35.8 \\
\hline Male & \multicolumn{2}{|c|}{70.0} & \multicolumn{2}{|c|}{33.3} & \multicolumn{2}{|c|}{88.9} & \multicolumn{2}{|c|}{80.0} & \multicolumn{2}{|c|}{92.9} & \multicolumn{2}{|c|}{40.0} & 64.2 \\
\hline \multicolumn{14}{|l|}{ Education \% } \\
\hline none & \multicolumn{2}{|c|}{0.0} & \multicolumn{2}{|c|}{3.3} & \multicolumn{2}{|c|}{0.0} & \multicolumn{2}{|c|}{0.0} & \multicolumn{2}{|c|}{7.1} & \multicolumn{2}{|c|}{0.0} & 1.6 \\
\hline primary & \multicolumn{2}{|c|}{76.7} & \multicolumn{2}{|c|}{43.3} & \multicolumn{2}{|c|}{44.4} & \multicolumn{2}{|c|}{60.0} & \multicolumn{2}{|c|}{57.1} & \multicolumn{2}{|c|}{0.0} & 60.2 \\
\hline secondary & & 1.7 & & 0.0 & & & & & & 5.7 & & & 29.3 \\
\hline higher & & .7 & & 3.3 & & & & & & .0 & & & 8.9 \\
\hline $\begin{array}{l}\text { Practice agriculture } \\
\text { using pesticides \% }(n)\end{array}$ & 35.1 & $(20.0)$ & 39.3 & $(11.0)$ & 25.0 & $(2.0)$ & 40.0 & $(2.0)$ & 46.2 & $(6.0)$ & 0.0 & - . & $35.3(41.0)$ \\
\hline $\begin{array}{l}\text { Live close to chemical } \\
\text { storage } \%(n)\end{array}$ & 58.3 & $(35.0)$ & 44.8 & $(13.0)$ & 33.3 & $(3.0)$ & 0.0 & - . & 38.5 & $(5.0)$ & 0.0 & - . & $46.3(56.0)$ \\
\hline Protection index & 0.8 & $(0.1)$ & 0.5 & $(0.3)$ & 0.6 & $(0.2)$ & 0.6 & $(0.2)$ & 0.5 & $(0.2)$ & 0.3 & $(0.2)$ & $0.6(0.2)$ \\
\hline EpiStress (SD) & 8.9 & (4.3) & 7.3 & (5.6) & 8.7 & $(4.2)$ & 8.6 & $(4.6)$ & 8.3 & $(4.6)$ & 8.0 & $(2.2)$ & $8.4(4.6)$ \\
\hline
\end{tabular}

ascertain which set of scores were more likely to be associated with 'higher versus lower exposure' (dichotomous dependent variable), if any (Step 4e). To ascertain the impact of including the EpiStress measure, we considered definitions both with and without this measure.

Following the previous exploratory analyses, next we used canonical discriminant analysis (Step 4f), which allows identifying a set of variables that optimally separates or distinguishes two groups. Based on our premise that we are observing two distinct groups of workers given their level of exposure, we aimed to identify which set of tests and symptoms (i.e., battery of tests), if any, best discriminates between higher and lower exposed groups.

Finally, we addressed the main research question by calculating the sensitivity and specificity of various combinations of low-cost tests (or various definitions of a positive Pentox test plus or minus low-cost blood tests) as potential screening tests for the various case definitions described using the Fisher's exact test (Step 5).

All analyses were performed using SAS 9.1.3.

\section{Results}

As noted above, after removing 37 cases (23.1\%) with medical conditions or with tobacco and alcohol use, a total of 123 floriculture workers from two floriculture plantations between the ages of 18-69 were included in the study. Twenty-three participants met the definition of 'high exposure' including all components. As shown in Table 1, the average age of workers was 32.6 ( $\mathrm{SD}=9.7$ years). The majority of the study population was male $(64.2 \%)$, and $60.2 \%$ of workers had only a primary school education. The most recent occupational profiles of the workers indicated that $48.8 \%$ worked in rose cultivation; $24 \%$ worked in postharvest, cold-room, and packaging; $7.3 \%$ worked in fumigation; $4.1 \%$ worked in fertilization, irrigation, and compost; $11.4 \%$ worked in service and maintenance; and $4.1 \%$ worked in administration. The average amount of time spent working in floriculture was 8.8 ( $\mathrm{SD}=5.1$ years); $46.3 \%$ of workers reported living near a factory or chemical storehouse where chemicals and insecticides were kept and applied, and $35.3 \%$ practiced domestic agriculture using pesticides.

When asked to report pesticides used on the farm, about $40 \%$ of workers were able to give a specific answer, and only about $13 \%$ of workers were able to respond when asked which label of pesticides they most frequently use. Of the respondents, $14 \%$ reported using OP (Orthene, Basudin, Malathion, Perfekthion); 27.5\% reported using carbamates (Furadan, Methavin, Mancozeb, Methomyl, Methoicarb); and 17.6\% reported using other known carcinogens (Mirage [glyphosate], Captan [thiophthalimide], Rovral [Iprodione], Mavrik [Sulfuron]). Of 16 respondents, $81.3 \%$ reported using toxic label pesticides, which also include OP, carbamate compounds, and pesticides with other toxic mechanisms.

We summarized the level of protection in an index ranging from 0 for no protection to 1 for full protection; Table 1 shows that the protection index tended to be quite low for jobs considered to be high exposure such as post-harvest, fumigation, and fertilization $(0.5,0.6$, and 0.6 respectively). In Table 1 we also report the values of EpiStress by occupation. The overall mean value for all occupations was $8.4(\mathrm{SD}=4.6)$.

The factor analysis on all tests and symptoms identified three main factors explaining more than $59 \%$ of the total variance. Based on the factor 
loadings shown in Table 2, we found that all symptoms loaded on the first factor, some blood tests (of the hematopoietic-hepatic-renal systems) load on the second factor, and other blood tests (white blood cells) load on the third factor. Most of the NES2 tests as well as the AChE test loaded poorly on all three factors.

Next we assessed how these three 'health effect' factors are related to exposure groups; in other words, which of these three factors was more likely to be associated with higher exposure. A logistic regression of our full exposure group definition, which includes the protection index and the EpiStress index, on the three factor scores (factor scores for each individual can be seen as index values representing a linear combination of tests or symptoms weighted by their respective factor loadings) shows only the first set of factor scores as being significant $(\mathrm{P}<0.05$; Hosmer and Lemeshow goodness-of-fit test $\mathrm{P}>0.67)$. High values of factor scores that were mostly weighted by selfreported symptoms were more than 2.2 times $(95 \% \mathrm{CI}$

Table 2 Factor loadings of all tests and symptoms

\begin{tabular}{|c|c|c|c|}
\hline Tests and Symptoms & Factor1 & Factor2 & Factor3 \\
\hline Decreased ability in hands & 0.70 & & \\
\hline Numbness & 0.65 & & \\
\hline Weakness & 0.65 & & \\
\hline Hand Tremors & 0.61 & & \\
\hline Sweating & 0.56 & & \\
\hline Dizziness & 0.55 & & \\
\hline Nausea & 0.52 & & \\
\hline Headaches & 0.49 & & \\
\hline Irritable & 0.46 & & \\
\hline Shortness of breath & 0.46 & & \\
\hline Stomach cramps & 0.45 & & \\
\hline Fainting & 0.44 & & \\
\hline Diarrhea & 0.40 & & \\
\hline Skin Irritation & 0.38 & & \\
\hline Eyes, nose \& throat irritation & 0.37 & & \\
\hline Salivation & 0.35 & & \\
\hline AChE value & $*$ & & \\
\hline Basophils & $*$ & & \\
\hline Hematocrit & & 0.93 & \\
\hline Hb level & & 0.93 & \\
\hline Red Blood Cells & & 0.90 & \\
\hline Creatinine & & 0.47 & \\
\hline Liver enzyme test: AST & & 0.40 & \\
\hline Liver enzyme test: ALT & & 0.34 & \\
\hline Finger taps & & $*$ & \\
\hline Hand eye coordination & & * & \\
\hline Symbol digit latency & & $*$ & \\
\hline Reaction time & & $*$ & \\
\hline Leukocytes values & & & 0.96 \\
\hline Neutrophil counts & & & 0.81 \\
\hline Monocytes & & & 0.64 \\
\hline Lymphocytes & & & 0.55 \\
\hline Pattern Memory & & & 0.28 \\
\hline
\end{tabular}

* Low factor loadings on all three factors

In order to assess whether there is a natural grouping of tests and symptoms for the whole sample, we performed a factor analysis that included all such tests and symptoms on all study participants. As presented in details in the results section, three distinct factors were identified and three sets of factor scores were obtained for each individual as a linear combination of all intervening variables weighted by their factor loadings.
1.4-3.7) as likely to be associated with individuals with higher and more prolonged exposure who are underprotected and exposed to higher levels of environmental stressors. The other two sets of factor scores were not significant. We did a similar logistic regression analysis using an exposure definition that did not include EpiStress and found that none of the health effect factors were more likely to be associated with exposure. The canonical discriminant analysis also confirmed the existence of two distinct exposure groups defined including EpiStress; it also showed that the tests that most contributed to the separation of the groups (Mahalanobis distance for squared distance between the group centers or means is highly significant; $\mathrm{P}<0.001$ ) were blood tests (hemoglobin and hematocrit, with monocytes, lympohcytes, and leukocytes playing a much smaller role) and symptoms (data available on request). A canonical discriminant analysis of the exposed groups without EpiStress did not produce a function capable of significantly separating the two groups. As such, we decided to keep EpiStress in the case definition of an individual who may be suffering health effects attributable to occupational and environmental exposures.

The results for the 23 participants who met this definition of 'highly exposed' were compared to those of the 100 subjects qualified as with low exposure. Table 3 reports symptoms for workers in cultivation, post-harvest packaging or cold room and fumigation jobs with more than four years in floriculture, who had a low protection index (index $<0.9$ ) and had high stressor levels (EpiStress $>10$ ) compared to those with lower exposure. More than $50 \%$ of respondents reported ear, nose, and throat irritation, irritability, and headaches $(83.6 \%, 64.2 \%$, and $59.3 \%$, respectively). Half of the 16 symptoms reported show a significantly higher incidence in the higher exposed group; these were irritability, headaches, salivation, weakness, stomach cramps, decreased ability in hands, diarrhea, and lightheadedness $(\mathrm{P}<0.05)$. Table 3 also shows a significantly higher reporting of multiple symptoms in the higher exposed group (with EpiStress). For instance, 78.3\% of the higher exposed workers, versus $31 \%$ of the lower exposed workers reported seven symptoms or more $(\mathrm{P}<0.0001)$. Close to $50 \%$ of respondents reported six symptoms or more.

The results of the clinical test batteries, as shown in Table 4, actually revealed fewer workers in the higher risk group showing abnormal AChE than in the lower risk group. However, higher exposed workers showed almost consistently more abnormal results overall in virtually all tests and batteries of tests compared to the low-exposure group. Some batteries detected highly significant differences such as a positive screen defined as 'abnormal AChE or at 
Table 3 Reported Symptoms by Exposure Group Including Protection Index and EpiStress Index

\begin{tabular}{|c|c|c|c|c|}
\hline $\begin{array}{l}\text { Self-reported } \\
\text { symptom in past week }\end{array}$ & $\begin{array}{l}\text { \% Reporting } \\
\text { Symptom }\end{array}$ & $\begin{array}{l}\% \text { those at } \\
\text { High Risk* Reporting } \\
\text { Symptom }(n=23)\end{array}$ & $\begin{array}{l}\% \text { those at Lower } \\
\text { Risk Reporting } \\
\text { Symptom }(n=100)\end{array}$ & $p<$ \\
\hline Ear, nose and throat irritation & 83.6 & 91.3 & 81.8 & 0.360 \\
\hline Irritability & 64.2 & 87.0 & 59.0 & 0.015 \\
\hline Headaches & 59.3 & 87.0 & 53.0 & 0.004 \\
\hline Salivation & 43.1 & 65.2 & 38.0 & 0.021 \\
\hline Weakness & 40.7 & 73.9 & 33.0 & 0.001 \\
\hline Sweating & 38.2 & 39.1 & 38.0 & 1.000 \\
\hline Stomach cramps & 36.6 & 65.2 & 30.0 & 0.003 \\
\hline Dizziness & 36.1 & 43.5 & 34.3 & 0.472 \\
\hline Hand Tremmors & 35.0 & 52.2 & 31.0 & 0.088 \\
\hline Skin Irritation & 33.3 & 47.8 & 30.0 & 0.140 \\
\hline Numbness & 30.1 & 43.5 & 27.0 & 0.136 \\
\hline Decreased ability in hands & 30.1 & 52.2 & 25.0 & 0.021 \\
\hline Shortness of breath & 26.8 & 26.1 & 27.0 & 1.000 \\
\hline Nausea & 19.5 & 30.4 & 17.0 & 0.153 \\
\hline Diarreah & 12.3 & 26.1 & 9.1 & 0.037 \\
\hline Fainting & 3.3 & 13.0 & 1.0 & 0.021 \\
\hline \multicolumn{5}{|l|}{ Reporting several symptoms } \\
\hline At least 2 symptoms & 91.9 & 100.0 & 90.0 & 0.206 \\
\hline At least 3 symptoms & 79.7 & 95.7 & 76.0 & 0.043 \\
\hline At least 4 symptoms & 69.1 & 91.3 & 64.0 & 0.011 \\
\hline At least 5 symptoms & 56.1 & 82.6 & 50.0 & 0.005 \\
\hline At least 6 symptoms & 47.2 & 78.3 & 40.0 & 0.001 \\
\hline At least 7 symptoms & 39.8 & 78.3 & 31.0 & 0.000 \\
\hline At least 9 symptoms & 23.8 & 43.5 & 19.0 & 0.026 \\
\hline
\end{tabular}

Notes:

Protection index $<0.9$ considered poor protection

Stress index: EpiStress $>10$.

p-value based on Fisher's exact test for association between exposure and presence of symptom.

Null hypothesis: Higher- and lower-exposure individuals are equally likely to report a symptom.

*Higher exposure group=Individuals in cultivation, post-harvest packaging and cold room, and fumigation jobs AND have more than 4 years in floriculture, AND have low protection index $(<0.9)$ AND have high stress level (EpiStress $>10)$.

Mahalanobis distance for squared distance between the group centers or means is highly significant; $p<0.001$.

least one positive blood test or seven or more symptoms $(\mathrm{P}<0.01)$.' A definition of a positive screen consisting of Pentox alone with a cutoff point set at the median value was found for $74 \%$ of the higherexposed group as opposed to $38 \%$ of the lowerexposed group $(\mathrm{P}<0.002)$. The addition of blood tests to the Pentox screening maintained a significant difference between the two groups.

The first two columns in Table 5 show the sensitivity and specificity of various tests and test combinations in detecting 'heavily exposed' versus lower exposure, both including and excluding EpiStress. This again revealed the wisdom of including EpiStress in the exposure definition component of the case definition. The next four columns assess the sensitivity and specificity of the various test batteries in detecting a case of chronic pesticide poisoning when we consider alternate definitions of a 'case' as previously defined (we did not report values when the same tests were present both in the screening battery and in the case definition, to avoid tautologies). It can be seen that $\mathrm{AChE}$ alone had consistently low sensitivity across the definitions of cases and only modest specificity. In contrast, positive NES2 had high specificity but low sensitivity.
In considering a battery of various symptoms alone we see higher sensitivity and lower specificity for all case definitions when fewer symptoms are required for a positive screen. However, we also found a higher sensitivity in case definitions that include EpiStress. When we consider batteries that include at least one positive NES2 test together with various symptoms, we observe a positive screen with even fewer symptoms. Again, including EpiStress in the case definitions improved the sensitivity and specificity of the tests. We also assessed the sensitivity and specificity of the Pentox instrument as a whole, defining abnormality at either the 25 th or 50 th percentile to ascertain which gave better results and how this compared to a positive screen defined by number of symptoms and/or blood tests. Table 5 shows that the only definitions of a positive screen that exceed $80 \%$ sensitivity and have at least 55\% specificity are '7 or more symptoms,' 'Pentox at greater than the 50th percentile,' or 'Pentox greater than $50 \%$ or (positive $\mathrm{AChE}$ and at least one positive blood test)' - the latter having about the same sensitivity but a slightly lower specificity.

For additional clarity, we have summarized our analyses and findings based on our objectives in 
Table 4 Test Results by Exposure Group Including Protection Index and Stress Index

\begin{tabular}{|c|c|c|c|c|}
\hline Test & $\begin{array}{l}\% \text { having } \\
\text { positive test }\end{array}$ & $\begin{array}{l}\% \text { those at High } \\
\text { Risk* Having Positive } \\
\text { Test }(n=23)\end{array}$ & $\begin{array}{l}\% \text { those at Lower } \\
\text { Risk Having Positive } \\
\text { Ttest }(n=100)\end{array}$ & $p<$ \\
\hline AChE & 22.8 & 13.0 & 25.0 & 0.278 \\
\hline At least one NES2 tests & 66.7 & 78.3 & 64.0 & 0.227 \\
\hline At least two NES2 tests & 40.7 & 43.5 & 40.0 & 0.816 \\
\hline At least three NES2 tests & 17.9 & 17.4 & 18.0 & 1.000 \\
\hline Blood tests & & & & \\
\hline AST & 25.2 & 21.7 & 26.0 & 0.794 \\
\hline ALT & 11.4 & 17.4 & 10.0 & 0.295 \\
\hline Hemoglobin & 15.4 & 21.7 & 14.0 & 0.349 \\
\hline WBC & 11.4 & 17.4 & 10.0 & 0.295 \\
\hline Creatinine & 1.6 & 0.0 & 2.0 & $\mathrm{n} / \mathrm{a}$ \\
\hline At least 1 positive blood test & 48.8 & 56.5 & 53.0 & 0.490 \\
\hline $\begin{array}{l}\text { Positive AChE or at least } 1 \text { positive } \\
\text { blood test, and } 7+\text { symptoms }\end{array}$ & 15.4 & 30.4 & 12.0 & 0.050 \\
\hline $\begin{array}{l}\text { Positive AChE or at least } 1 \text { positive } \\
\text { blood test or } 7+\text { symptoms }\end{array}$ & 58.5 & 82.6 & 53 & 0.010 \\
\hline PENTOX $=>25$ th percentile cutoff & 70.7 & 87.0 & 67.0 & 0.075 \\
\hline PENTOX $=>50$ th percentile cutoff & 44.7 & 73.9 & 38.0 & 0.002 \\
\hline $\begin{array}{l}\text { PENTOX }=>25 \text { th } \% \text { or (positive ACHE and } \\
\text { at least one positive blood test) }\end{array}$ & 74.0 & 91.3 & 70.0 & 0.037 \\
\hline $\begin{array}{l}\text { PENTOX }=>50 \text { th } \% \text { or (positive ACHE and } \\
\text { at least one positive blood test) }\end{array}$ & 49.6 & 78.3 & 43.0 & 0.003 \\
\hline PENTOX $=>25$ th $\%$ or positive ACHE & 77.2 & 91.3 & 74.0 & 0.099 \\
\hline PENTOX $=>50$ th $\%$ or positive ACHE & 56.1 & 78.3 & 51.0 & 0.020 \\
\hline $\begin{array}{l}\text { PENTOX }=>25 \text { th } \% \text { and at least } \\
\text { one positive blood test }\end{array}$ & 33.33 & 47.8 & 30.0 & 0.140 \\
\hline $\begin{array}{l}\text { PENTOX }=>25 \text { th } \% \text { or at least one } \\
\text { positive blood test }\end{array}$ & 86.18 & 95.7 & 84.0 & 0.192 \\
\hline $\begin{array}{l}\text { PENTOX }=>50 \text { th } \% \text { and at least one } \\
\text { positive blood test }\end{array}$ & 21.14 & 39.1 & 17.0 & 0.026 \\
\hline $\begin{array}{l}\text { PENTOX }=>50 \text { th } \% \text { or at least one } \\
\text { positive blood test }\end{array}$ & 72.36 & 91.3 & 68.0 & 0.036 \\
\hline
\end{tabular}

Notes:

Protection index $<0.9$ considered poor protection.

Stress index: EpiStress $>10$.

p-value based on Fisher's exact test for association between exposure and positive test battery.

Null hypothesis: Highe-r and lower-exposure individuals are equally likely to have a positive test.

*Higher exposure group=Individuals in cultivation, post-harvest packaging and cold room, and fumigation jobs AND have more

than 4 years in floriculture, AND have low protection index $(<0.9)$ AND have high stress level (EpiStress $>10)$.

Mahalanobis distance for squared distance between the group centers or means is highly significant; $p<0.001$.

Table 6, indicating the statistical methods used as well in Figure 1.

\section{Discussion and conclusion}

The need to reduce pesticide exposure is widely accepted, ${ }^{36,37}$ yet one of the challenges has been difficulty in measuring both exposures and effects, let alone relating effects to exposures, or even more importantly, having a low-cost screening test that can be applied in the field to screen for toxic effects from pesticide exposure. ${ }^{38}$ Our study was conducted toward the goal of better detection and monitoring of chronic pesticide poisoning, and ultimately exposure reduction and elimination. While the work of SALTRA has contributed considerably to this goal, the fact remains that much illness in agricultural communities that may be linked to pesticide exposure remains undiagnosed as such.

As we recognized that defining a case in this study using some of the same tests included in a possible screening battery would suggest a possible tautology, we strictly avoided this approach. Rather, as there is no internationally accepted gold standard, and as the literature indicates that persistent low-dose pesticide exposure is associated with hematological, ${ }^{39}$ immunological, ${ }^{39}$ renal, ${ }^{39}$ and hepatic effects, ${ }^{39}$ among others, ${ }^{40}$ not merely neurotoxic effects, ${ }^{41}$ we decided to ascertain how various tests perform with different definitions of 'a case.' The finding of significant differences in health profiles by exposure groups of floriculture workers presents a convincing reason for pursuing this line of research. Factor analysis suggested 


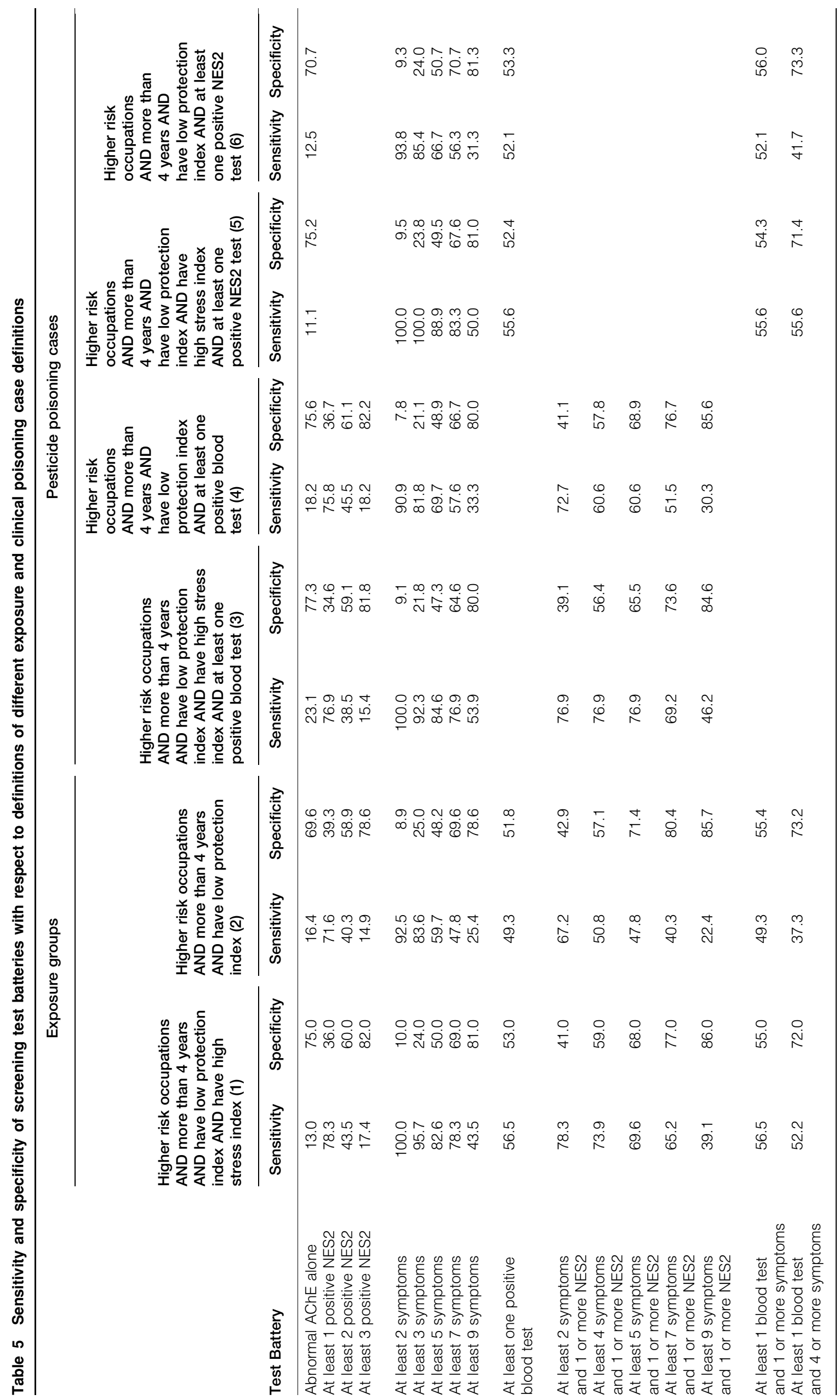


Breilh et al. Chronic pesticide poisoning in Ecuadorean floriculture workers

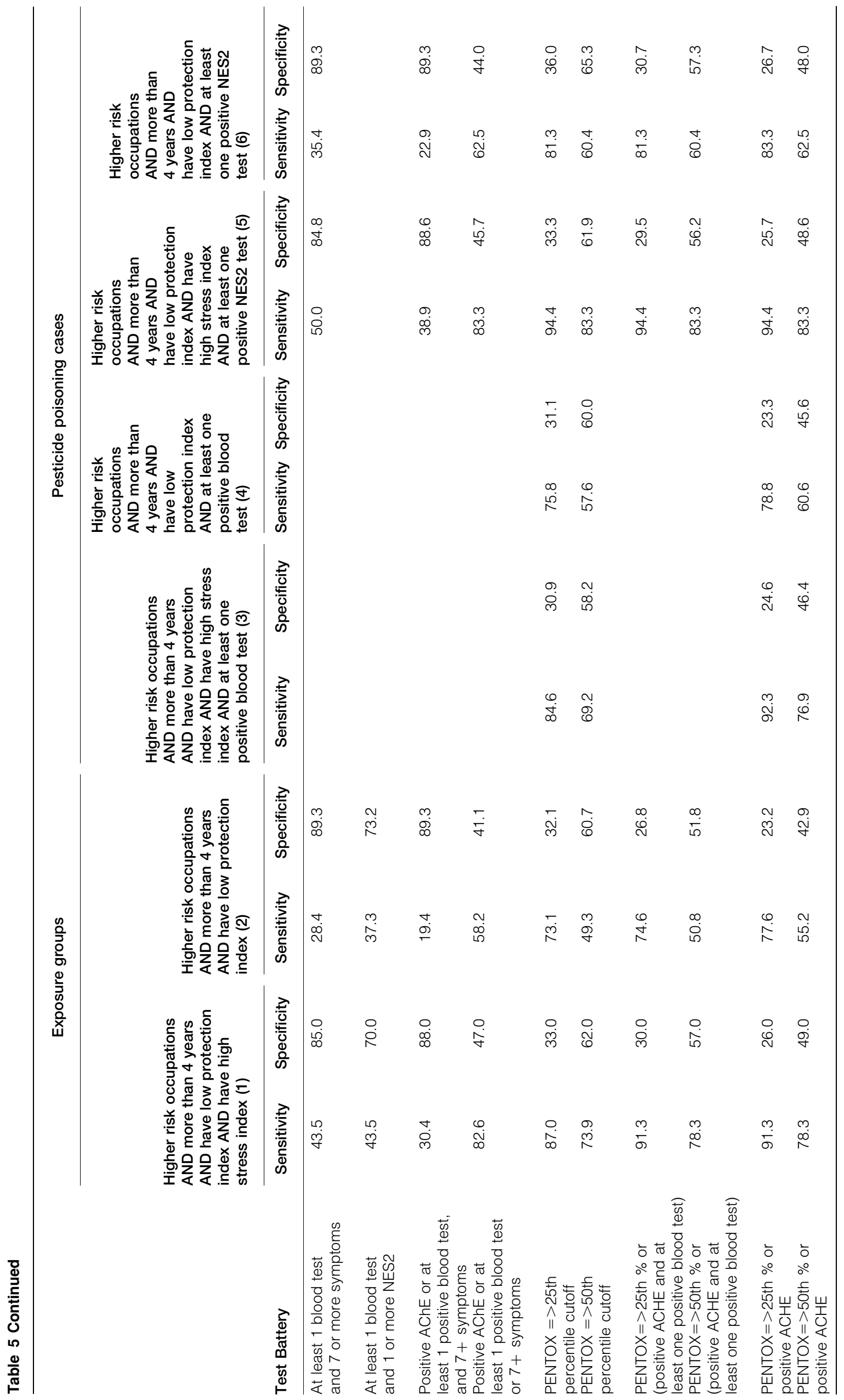

International Journal of Occupational and Environmental Health 2012 VOL. 18 
Breilh et al. Chronic pesticide poisoning in Ecuadorean floriculture workers

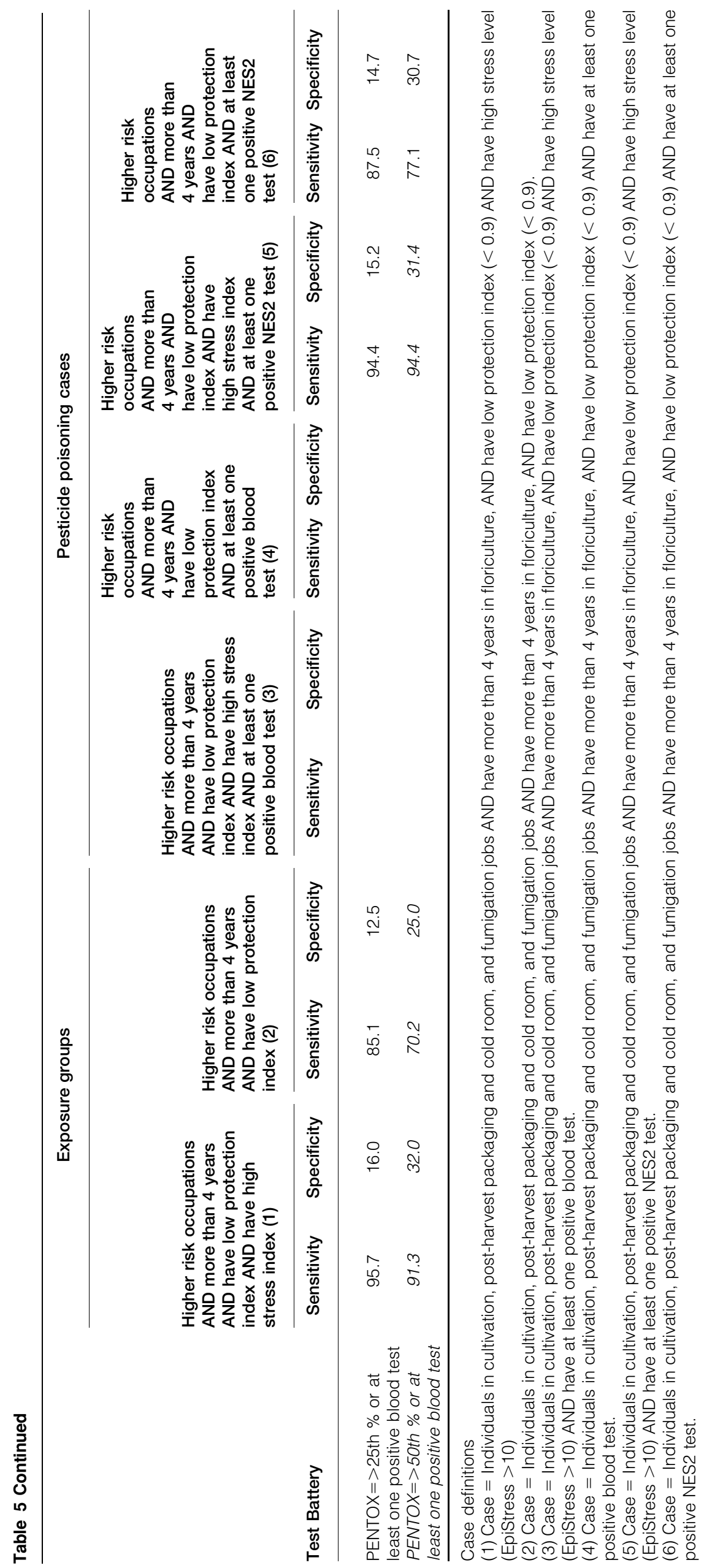


융 ᄃ효

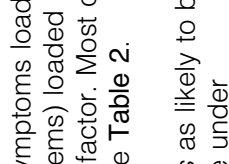

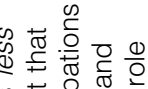

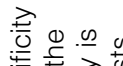



बक के

कि

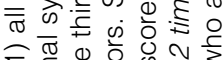

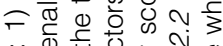

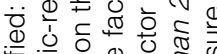

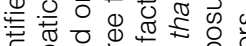

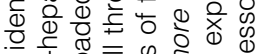

o. 으

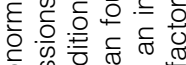

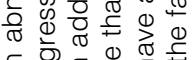

言通.



을

豞

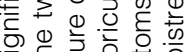

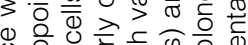

क







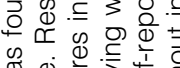



造 d

का

등응

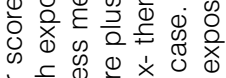

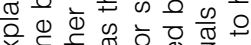

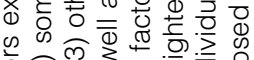



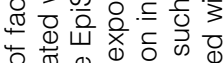

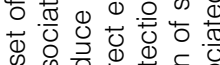

क

产

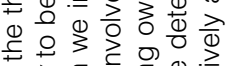

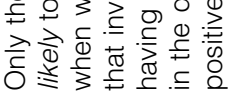

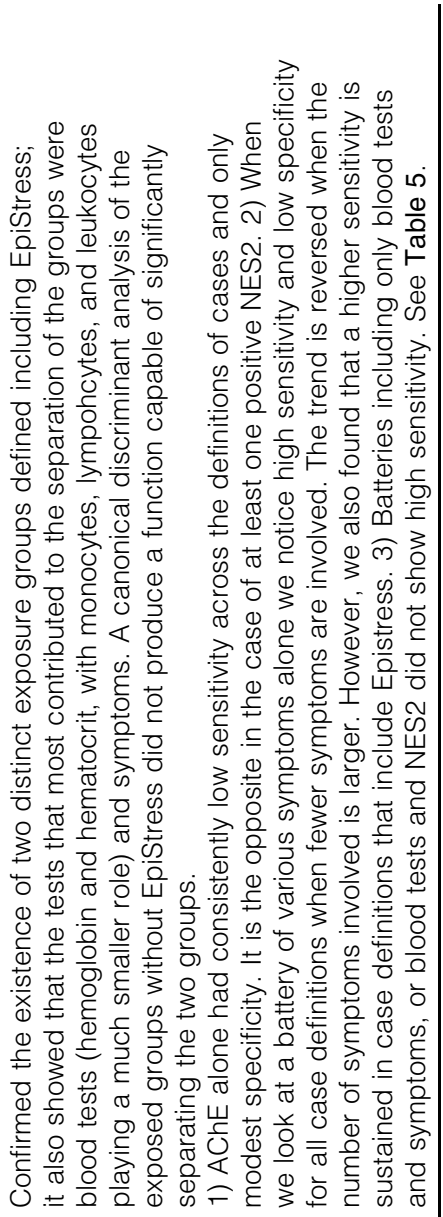

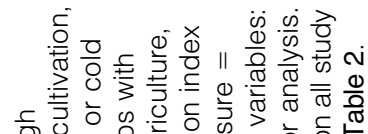

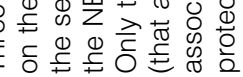



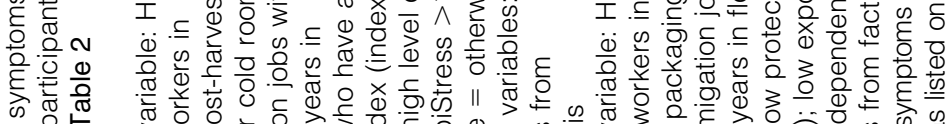

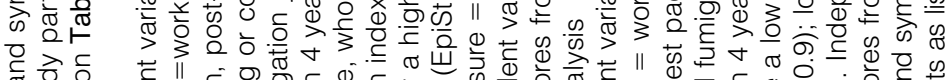

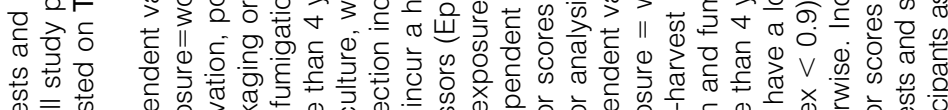

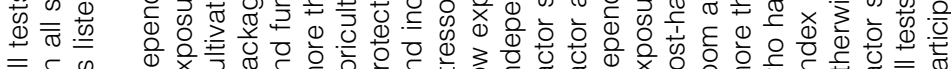

须品

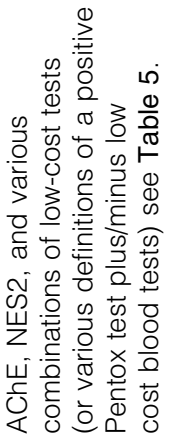
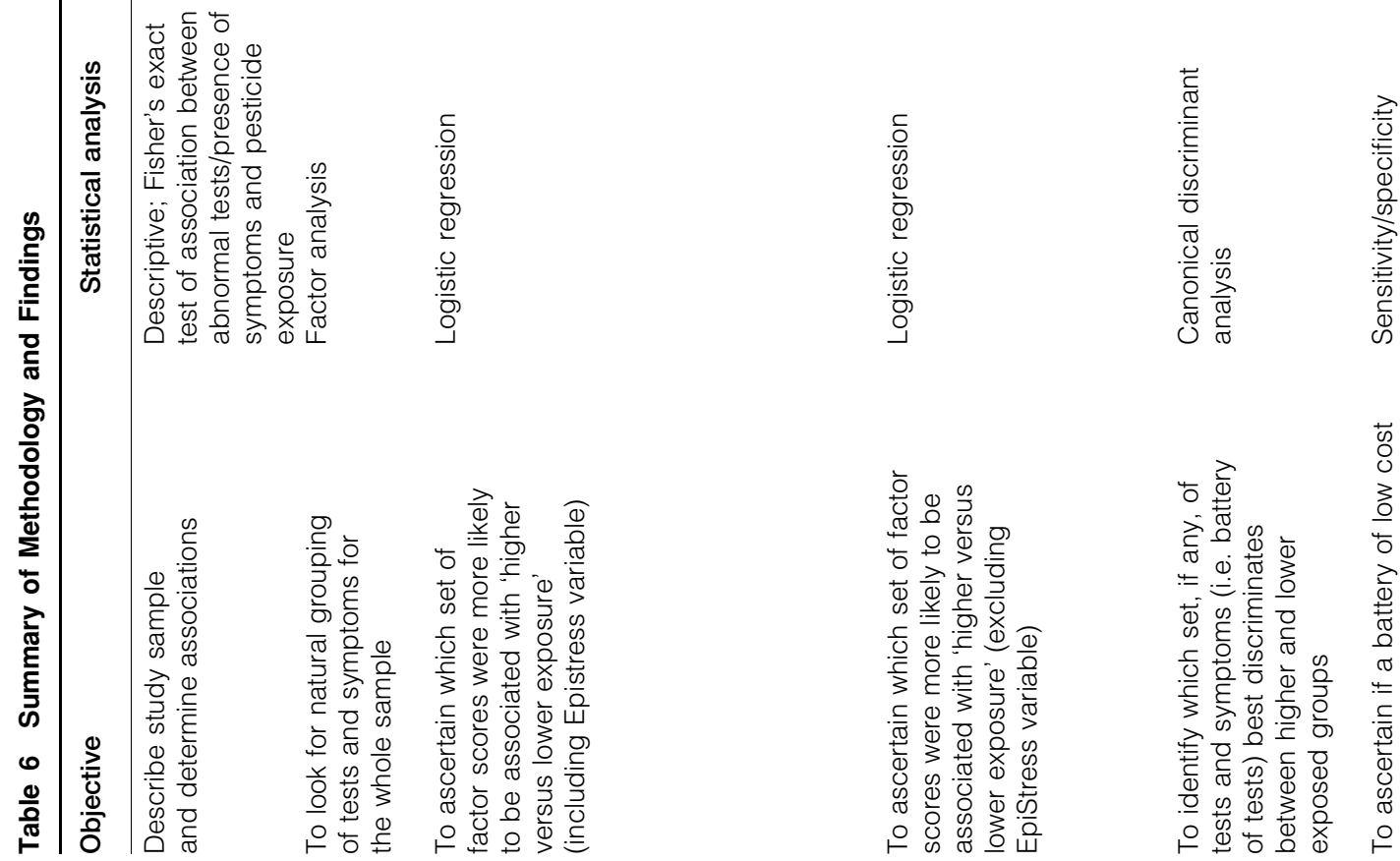

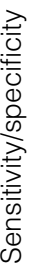



范

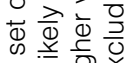

웡





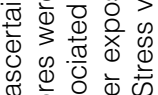

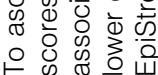

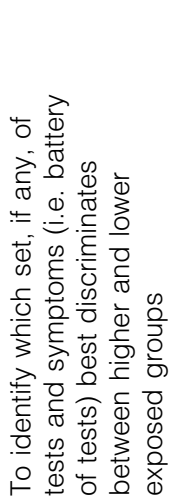



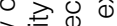

글

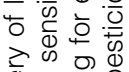

可这.

o d \&

닝

돌 है응

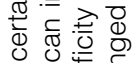

of o :

웡 
three factors, explaining more than $59 \%$ of the total variance. The addition of another factor did not significantly increase the total variance explained, suggesting that three factors are sufficient. The fact that we find that there are different manifestations of pesticide poisoning -i.e., symptoms (possibly reflecting what is commonly thought of as acute pesticide poisoning, but possibly reflecting chronic cumulative toxicity underlying these symptoms); systemic toxicity with abnormal hematological and hepatic function; and abnormal leukocytic profile - is not surprising, given the vast variety of different chemicals in use and individual variations.

We present our data with case definitions that both include and exclude a measure of concomitant exposures. Which is the 'correct' way to proceed is a policy not a scientific question, and one based on the purpose of the exercise. Specifically, if the goal would be identifying 'strictly occupational pesticide poisoning' (e.g., for purposes of determining causation in jurisdictions where workers' compensation requires that kind of a distinction), rather than a case of chronic pesticide poisoning for prevention purposes that takes into account different concurrent exposures and individual susceptibility, one would not include EpiStress. With the goal of prevention of deleterious effects in agricultural workers, we felt that taking individual variability and concomitant stressors into account is indeed appropriate.

Others have noted that a single measurement of $\mathrm{AChE}$ is inadequate to detect chronic pesticide poisoning; ${ }^{19,42}$ our findings support this and lead to the conclusion that the conventional procedure many employers and even health services use of a single measurement of $\mathrm{AChE}$ is insufficient and a new screening battery is needed. We have found that including EpiStress, (or an equivalent tool, to include otherwise confounding domestic exposures), and using a simple instrument such as Pentox, in addition to basic low-cost blood tests and the single AChE measure, can improve sensitivity and specificity of screening, and is worth further exploration. Because we strictly avoided defining 'a case' of chronic pesticide exposure using any of the tests that are included in any of the batteries examined, the sensitivities and specificities reported in the tables are quite conservative.

In the context of global social and economic forces, the increasing trend in pesticide use and hazardous productive technologies is indeed well-documented. ${ }^{43}$ As noted by SALTRA (Wesseling et al. ${ }^{46}$ ), building capacity of occupational health personnel, strengthening university-community partnerships, and raising political awareness, are all crucial, as is strengthening epidemiological surveillance. Recognizing this, the parties involved in this study have been actively involved in creating a community of practice capable of taking on this challenge in Ecuador in partnership with broader networks. ${ }^{44}$ While it is necessary to more systematically address the determinant processes that are responsible for pesticide poisoning, as well as the options for sustainable and safe production, more study is also specifically warranted on the long-term effects from exposure to various classes of pesticides in low doses and low-cost health indicators and biomarkers that suggest such ill health effects before adverse changes occur.

We recognize the relatively small sample size with the inclusion of multiple variables related to exposure, laboratory markers, and self-reported questionnaires as limitations of the study. However, this study constitutes an important contribution to developing a low-cost tool to detect chronic pesticide poisoning using an integrated approach that the multifactorial problem of pesticide poisoning requires. While more research is warranted we believe that a simple lowcost test battery, including Pentox, should be considered in the screening protocols.

\section{Acknowledgements}

This study was funded by the International Development Center (Canada), Centro de Estudios y Asesoría en Salud (Ecuador), and the Universidad Andina Simón Bolívar (Quito, Ecuador).

We are grateful for the financial and technical support provided by the International Development Research Center; the contributions to project design plus sample collection and laboratory work provided by CEAS in Ecuador; and specifically Arturo Campaña, Orlando Felicita and María de Lourdes Larrea for their enormous contributions. We also acknowledge the work of Gustavo Teran and his BIODILAB Laboratory System for the clinical blood sample processing. We are grateful to the faculty and staff at the Univerity of British Columbia, for their assistance including Jerry Spiegel, Karen Lockhart, Michael Lathuilliere, Nadine Straka, and Arnaldo Sanchez who played a particularly enourmous role in helping to revise the manuscript for final submission. Finally, we thank the workers who participated in this study for their willingness to contribute to research that will strengthen world knowledge and ultimately improve environmental and occupational health in the agro-industry.

Disclosures: The authors declare no conflict of interest.

\section{References}

1 Breilh J. New model of accumulation and agro-business: the ecological and epidemiological implications of the Ecuadorian cut flower production. Cien Saude Colet 2007;12(1):91-104. 
2 Instituto Nacional de estadistica y censos (INEC). Encuesta de Superficie y Producción Agropecuaria. www.inec.gov.ec, 2008.

3 World Health Organization. The WHO Recommended Classification of Pesticides by Hazard and Guidelines to Classification 2004. Geneva, 2005.

4 Peres F, Moreira J. E Veneno ou e Remedio? Rio de Janeiro: Editora FIOCRUZ, 2003.

5 Tilman D. The greening of the green revolution. Nature 1998;396:211-12.

6 London L, Myers JE. Critical Issues for Agrichemical Safety in South-Africa. Am J Indust Med 1995;27(1):1-14.

7 Dasgupta S, Meisner C, Wheeler D, Xuyen K, Lam NT. Pesticide poisoning of farm workers - implications of blood test results from Vietnam. Int J Hyg Environ Health 2007;210(2):121-32.

8 Yassin MM, Abu Mourad TA, Safi JM. Knowledge, attitude, practice, and toxicity symptoms associated with pesticide use among farm workers in the Gaza Strip. Occup Environ Med 2002;59(6):387-93.

9 Chitra GA, Muraleedharan VR, Swaminathan T, Veeraraghavan D. Use of pesticides and its impact on health of farmers in South India. Inter J Occup Environ Health 2006;12(3):228-33.

10 Hurtig AK, Sebastian MS, Soto A, Shingre A, Zambrano D, Guerrero W. Pesticide use among farmers in the Amazon Basin of Ecuador. Arch Environ Health 2003;58(4):223-28.

11 Cole DC, Sherwood S, Crissman C, Barrera V, Espinosa P. Pesticides and health in highland Ecuadorian potato production: Assessing impacts and developing responses. Inter J Occup Environ Health 2002;8(3):182-90.

12 Paz-y-Mino C, Arevalo M, Sanchez ME, Leone PE. Chromosome and DNA damage analysis in individuals occupationally exposed to pesticides with relation to genetic polymorphism for CYP 1A1 gene in Ecuador. Mutation Research-Genetic Toxicol Environ Mutagenesis 2004;562(12):77-89.

13 Gomez-Arroyo S, Diaz-Sanchez Y, Meneses-Perez MA Villalobos-Pietrini R, De Leon-Rodriguez J. Cytogenetic biomonitoring in a Mexican floriculture worker group exposed to pesticides. Mutation Research-Genetic Toxicology and Environmental Mutagenesis 2000;466(1):117-24.

14 Lucero L, Pastor S, Suarez S, Durban R, Gomez C, Parron T, et al. Cytogenetic biomonitoring of Spanish greenhouse workers exposed to pesticides: micronuclei analysis in peripheral blood lymphocytes and buccal epithelial cells. Mutation ResearchGenetic Toxicol Environ Mutagenesis 2000;464(2):255-62.

15 Gomes J, Dawodu AH, Lloyd O, Revitt DM, Anilal SV. Hepatic injury and disturbed amino acid metabolism in mice following prolonged exposure to organophosphorus pesticides. Hum Exp Toxicol 1999;18(1):33-37.

16 Michalek JE, Ketchum NS, Longnecker MP. Serum dioxin and hepatic abnormalities in veterans of operation ranch hand Annals Epidem 2001;11(5):304-11.

17 Safi JM, Abu Mourad TA, Yassin MM. Hematological biomarkers in farm workers exposed to organophosphorus pesticides in the Gaza Strip. Archives of Environ Occup Health 2005;60(5):235-41

18 Wesseling C, Keifer M, Ahlbom A, McConnell R, Moon JD, Rosenstock L, et al. Long-term neurobehavioral effects of mild poisonings with organophosphate and n-methyl carbamate pesticides among banana workers. Inter J Occup Environ Health 2002;8(1):27-34.

19 al-Saleh IA. Pesticides: a review article. J Environ Pathol Toxicol Oncol 1994;13(3):151-61.

20 McCauley LA, Anger WK, Keifer M, Langley R, Robson MG Rohlman D. Studying health outcomes in farmworker populations exposed to pesticides. Environ Health Perspectives 2006;114(6):953-60

21 Bravo V, Rodríguez $\mathrm{T}$, van Wendel de Joode $\mathrm{B}$, Canto $\mathrm{N}$, Calderón GR, et al. Monitoring Pesticide Use and Associated Health Hazards in Central America. Inter J Occup Environ Health 2011;17(3):258-69.

22 Asamblea Constituyente del Ecuador. Nueva Constitucion. In: Ecuador ACd, editor, 2008.

23 Sackett D, Haynes BR, Tugwell P, Guyatt G. Clinical Epidemiology: A Basic Science for Clinical Medicine, 1991.

24 Curl CL, Fenske RA, Kissel JC, Shirai JH, Moate TF, Griffith $\mathrm{W}$, et al. Evaluation of take-home organophosphorus pesticide exposure among agricultural workers and their children. Environ Health Perspect 2002;110(12):A787-A92.
25 Relyea RA, Mills N. Predator-induced stress makes the pesticide carbaryl more deadly to gray treefrog tadpoles (Hyla versicolor) The National Academy of Sciences, 2001.

26 NIOSH Working Group. Stress at Work. Cincinnati: Centers for Disease Control and Prevention, 2011.

27 de Pablos RM, Villaran RF, Arguelles S, Herrera AJ, Venero JL, Ayala A, et al. Stress increases vulnerability to inflammation in the rat prefrontal cortex. J Neurosci 2006;26(21):5709-19.

28 Breilh J, Campana A, Felicita O, et al. Environmental and Health Impacts of Floriculture in Ecuador. Research Report Project IDRC-CRDI (103697-001) Quito: CEAS, 2009.

29 Breilh J. Trabajo Hospitalario, Estrés y Salud. México: Revista 'Salud Problema.' 1993;23:21-27.

30 Breilh J. Trabajo Hospitalario, Estrés y Sufrimiento Mental: El Deterioro de la Salud de los Internos en Quito, Ecuador. Cuenca: Revista de la Facultad de Ciencias Médicas, Cuenca: Revista Ateneo del Colegio de Médicos del Azuay 2009;14(4):819.

31 Letz R. Advances in neurobehavioural toxicology: Applications in environmental and occupcational health. Chelsea: Lewis Publishers, 1990.

32 Letz R. The neurobehavioral evaluation system: an international effort. In: Johnson B, editor. Advances in neurobehavioral toxicology: applications in occupational and environmental health. Chelsea, Michigan: Lewis Publishing Co., 1990:189-201.

33 Schwartz B, Bolla K, Stewart W,al. e. Decrements in neurobehavioral performance associated with mixed exposure to organic and inorganic lead. Am J Epidemiol 1993;137:1006-21.

34 Tsai S-Y, Chen J-D. Neurobehavioral effects of occupational exposure to low-level styrene. Neurotoxicol Teratol 1996;18:463-9.

35 Anger WK. Neurobehavioural tests and systems to assess neurotoxic exposures in the workplace and community. Occup Environ Med 2003;60(7):531-8, 474.

36 Stephens R, Spurgeon A, Calvert IA, Beach J, Levy LS, Berry $\mathrm{H}$, et al. Neuropsychological effects of long-term exposure to organophosphates in sheep dip. Lancet 1995;345(8958):1135-9.

37 Sudakin DL, Power LE. Regional variation in the severity of pesticide exposure outcomes: applications of geographic information systems and spatial scan statistics. Clin Toxicol (Phila). 2009;47(3):248-52.

38 Stewart PA, Prince JK, Colt JS, Ward MH. A method for assessing occupational pesticide exposures of farmworkers. Am J Indust Med 2001;40(5):561-70.

39 Hernandez AF, Gomez MA, Perez V, Garcia-Lario JV, Pena $\mathrm{G}$, Gil F, et al. Influence of exposure to pesticides on serum components and enzyme activities of cytotoxicity among intensive agriculture farmers. Environ Res 2006:102(1):70-76.

40 Colosio C, Tiramani M, Maroni M. Neurobehavioral effects of pesticides: State of the art. Neurotoxicol 2003;24(4-5):577-91.

41 Stokes L, Stark A, Marshall E, Narang A. Neurotoxicity among pesticide applicators exposed to organophosphates. Occup Environ Med 1995;52(10):648-53.

42 Sanborn M, Kerr KJ, Sanin LH, Cole DC, Bassil KL, Vakil C. Non-cancer health effects of pesticides: systematic review and implications for family doctors. Can Fam Physician 2007; 53(10): 1712-20.

43 Breilh J, Campaña A, Hidalgo $\mathrm{F}$, et al. Floriculture and the health divide: a struggle for fair and ecological flowers. In: CEAS (ed.). Alternative Latin American Health Report. Quito: Latin American Health Watch, 2005, pp. 66-79.

44 Spiegel J, Breilh J, Beltran E, Parra J, Solis F, Yassi A, Rojas A, Orrego E, Henry B, Bowie W, Pearce L, Gaibor J, Velasquez P, Concepcion M, Parkes M. Establishing a community of practice of researchers, practitioners, policymakers and communities to sustainably manage environmental health risks in Ecuador. BMC International Health and Human Rights. 11(Suppl 2):S5. http://www.biomedcentral.com/1472698X/11/S2/S5

45 Breilh J. Latin America Health Watch: Alternative Latin America Health Report. People's Health Assembly. 2005.

46 Wesseling C, Aragón A, Elgstrand K, Flores R, Hogstedt C, Partanen T. SALTRA: A Regional Program for Workers' Health and Sustainable Development in Central America. Inter J Occup Environ Health 2011;17(3):223-29. 